\title{
FORMAÇÃO \\ DE GRUPOS EM UMA \\ TURMA DE PORTUGUÊS \\ COMO LÍNGUA \\ ESTRANGEIRA: QUANDO A \\ AMIZADE AJUDA O \\ APRENDIZADO
}

\section{LA FORMACIÓN DE GRUPOS EN UNA CLASE DE PORTUGUÉS COMO LENGUA EXTRANJERA: CUANDO LA AMISTAD AYUDA DE APRENDIZAJE}

\author{
GROUP FORMATION IN A CLASS OF PORTUGUESE AS A FOREIGN LANGUAGE: WHEN \\ FRIENDSHIP HELPS LEARNING
}

Eloisa Jardim Barino Ferraz ${ }^{*}$

Denise Barros Weiss**

Universidade Federal de Juiz de Fora

RESUMO: Este artigo objetiva mostrar como, em uma turma multiétnica de Português para alunos estrangeiros, formam-se grupos entre os alunos. Foram analisados dados colhidos em duas turmas de alunos intercambistas em uma universidade de Minas Gerais, Brasil, a partir de referenciais teóricos da Sociolinguistica Interacional e da geografia cultural. Por meio da triangulação de dados de mapas de sala, entrevistas com os alunos e diário de campo, observou-se longitudinalmente como se formaram os grupos na sala de aula e qual foi o impacto dessa formação no modo como esses alunos desenvolveram suas habilidades de fala e escuta de português. Observou-se que aqueles alunos que foram capazes de se relacionar com mais colegas na sala de aula foram os que desenvolveram mais suas habilidades de interação em língua portuguesa.

PALAVRAS-CHAVE: interação; português língua estrangeira; aprendizagem.

RESUMEN: Ese artículo objetiva mostrar como,en una clase multiétnica de Portugués para alumnos extranjeros, se forman grupos

\footnotetext{
* Mestre em Linguística pela UFJFe professorada Unipac-Barbacena. E-mail: eloisabarino@hotmail.com

** Denise Barros Weiss é doutora em Estudos Linguísticos pela UFF e professora da UFJF. E-mail: 
entre los alumnos. Se analizaron los datos recogidos en dos clases de alumnos de intercambio en una universidad de Minas Gerais, Brasil, desde referencias teóricas de SociolinguísticaInteraccional y Geografia Cultural .El analisis fue hecho a partir de la triangulación de dados de los mapas de clase, entrevistas con los alumnos y diario de campo. Observándose longitudinalmente como se formaron los grupos en el clase y cual fue el impacto de esa formación en el modo como esos alumnos desarrollaron sus habilidades de habla y escuche de Portugués. Se observó que aquellos alumnos que fueron capaces de relacionar con más colegas de clase fueron los qué se salieron mejor en la asignatura.

PALABRAS- CLAVE: interacción; portugués lengua extranjera; aprendizaje.

ABSTRACT: This article aims to show how groups of students are formed in a multiethnical class of Portuguese for Foreign Students. The data analyzed were collected from two classes of exchange students at a university of Minas Gerais, Brazil, departing from theoretical references of Interactional Sociolinguistics and Cultural Geography. It was longitudinally observed, by means of triangulation of data sources - classroom maps, interviews with students, and research diaries - how these classroom groups were formed and the extent to which this formation impacted the way these students develop their skills of listening and speaking in Portuguese. It was also observed that the students who were able to interact with more classmates in the classroom were the ones who most developed their interaction skills in Portuguese.

KEYWORDS: interaction; portuguese as a foreign language; learning.

\section{INTRODUÇÃO}

Neste artigo apresentamos um estudo sobre a formação de grupos de alunos de diferentes nacionalidades em turmas multiétnicas de português para estrangeiros.

Os dados aqui observados são resultantes da pesquisa que deu origem a uma dissertação de Mestrado intitulada "A dinâmica interacional entre discentes em turmas de Português como Língua Adicional" (BARINO, 2014), cujo foco foi a análise de situações de interação entre alunos estrangeiros aprendizes de português,que poderiam ocasionar reflexos positivos no processo de ensinoaprendizagem.

Foram analisados, por meio da observação em sala de aula, de gravação de sessões de trabalho e de entrevistas com alunos de diferentes origens que formaram turmas para aprendizagem de português como língua estrangeira em uma universidade mineira,episódios de interação entre grupos ou pares de discentes em que, de forma cooperativa, eles tiveram a possibilidade de se unirem para juntos avançarem no aprendizado e no desenvolvimento de tarefas.

A Sociolinguística Interacional foi a basedessa reflexão.Como ressalta Gumperz (1998, p.79), "[...] a abordagem sociolinguística interacional focaliza o jogo de pressuposições linguísticas, contextuais e sociais que interagem para criar condições para o aprendizado em sala de aula". Tal aprendizado deve ser visto a partir de concepções de educação explícitas em que se considere a dinâmica da relação aluno-aluno/aluno-professor como resultado de fatores internos e externos;assim, as múltiplas interações que verificamos em qualquer sala de aula deverão ser levadas em conta ao se observar como as relações interpessoais se desenvolvem nesse contexto.

O professor não deve ser considerado como único membro do grupo a exercer o papel de facilitador/condutor do aprendizado. O que se observou durante a pesquisa foi que os alunos também exercem a função de alavancadores da interação que proporciona $o$ acesso de colegas ao conhecimento. As atividades entre os alunos proporcionam oportunidades de interação em que muitas vezes se estabelece uma relação que se denomina "andaimagem" (scaffolding):

Embora Vygotsky não tenha usado o termo andaimagem, essa expressão tem sido usada por pesquisadores, psicólogos e estudiosos da área de educação que trabalham com a SCT [Teoria Sociocultural]. [...] O termo andaimagem se refere ao processo dialógico que ocorre quando falantes ajudam-se mutuamente para desempenhar funções ou atividades que de outra forma não poderiam desempenhar individualmente. (SILVA, 2006, p.15). 
Essas atividades em grupo, conforme Jacobs e Wards (2000), não são reflexos apenas de trabalhos em grupos realizados pelos discentes, mas envolvem ainda todas as estratégias e os recursos utilizados para aquisição de conhecimentos, tendo como base a interação aluno-aluno. Tal relação pode gerar uma interdependência positiva entre os alunos, já que eles desenvolvem habilidades compartilhadas, calcadas em uma participação igualitária na interação. Assim, um aluno considerado um membro mais experiente coordena as discussões, de acordo com a perspectiva vygotskyana destacada, mas outros membros também participam e compartilham impressões e ideias.

O espaço da sala de aula é nosso ambiente de análise. Por isso, consideramos necessário definir tal espaçocomo um espaço físico com características peculiares, como um local específico para aprendizagem (ambiente institucional) e, finalmente, como um espaço de socialização do indivíduo. Para tanto, recorremos à geografia, tomando dela a noção de lugar.

A metodologia utilizada é baseada na abordagem qualitativa, por intermédio de estudos de viés etnográfico. Segundo Oliveira (2008, p.1),

[...]a perspectiva etnográfica parte do que é fundamental e clássico no trabalho de campo com relação ao método qualitativo antropológico: observação participante, roteiro aberto de entrevista, contato direto e pessoal do pesquisador com os interlocutores de campo e período de campo relativamente longo.

Tal perspectiva exige uma postura interpretativa do pesquisador, já que é ele que está selecionando, descrevendo e observando os dados considerados relevantes para o entendimento da dinâmica das relações na escola, refletidas sob uma análise holística da situação.

Com essa pesquisa, esperamos compreender um pouco mais a maneira como são construídasas redes de relacionamento interpessoal entre os alunos, de forma a tentar desvendar alguns mecanismos da dinâmica dessa interação que nos permitam, ao dirimirmos dificuldades de relacionamento, atingir resultados mais satisfatórios no processo de ensino-aprendizagem em turmas de alunos estrangeiros de origens diferentes.

\section{PRESSUPOSTOS TEÓRICOS}

Nesta seção apresentaremos os principais conceitos empregados na pesquisa, tomando como base elementos da Sociolinguística Interacional, da qual usamos as noções de contexto e de enquadre. Das teorias sociais de aprendizagem, destacamos a aprendizagem colaborativa.A partir do olhar da geografia cultural, apresentamos, por fim, um conceito de cultura.

Nossa visão sobre o que é escola e a aprendizagem de línguas se coaduna parcialmente com a de Malamah-Thomas:

Aprender uma língua, como qualquer outra coisa, é essencialmente uma aquisição individual, uma exploração das capacidades da mente de compreender o ambiente. Mas tipicamente esse processo privado ocorre no contexto público da sala de aula, o indivíduo é um em um grupo, um membro da classe, e as atividades que encaminham o processo são determinados pelo professor. O que se considera é que esse processo interno virá como consequência da interação externa que ocorre entre dois tipos de participante: o professor de um lado e os alunos, de outro.1(MALAMAH-THOMAS, 1987, p. 3, tradução nossa)

Entretanto, acrescentamos a essa reflexão que, se o aluno está em um grupo, suas relações na sala de aula nunca se restringem à que tem com o professor. A presença dos colegas é fator preponderante em muitos dos processos que envolvem o aprendizado. Situações

1Learning a language, like the learning of anything else, is essencially an individual achievement, an exploitation of the capacities of the mind to make sense of the enviroment. But tipically this private process takes place in the public context of classroom, the individual is one of a group, a member of the class, and the activities which are to set the process in train are determined by the teacher. The assumption is that this internal process of learning will come about as a consequence of the external interaction which takes place between two kinds of participant: the teacher on one hand, and the learners on the other. 
corriqueiras, como a vergonha diante do colega que sabe mais, ou a ajuda providencial do amigo na hora de uma pergunta difícil ou de uma dúvida não resolvida pelo professor são exemplos da influência dos colegas nesse processo.

Esses fazem parte do contexto da sala de aula. Entendemos contexto seguindo os pressupostos da sociolinguística, como uma construção conjunta dos participantes de uma interação. É uma noção situada, estabelecida na interação dos participantes.

Um contexto pode ser conceptualizado não simplesmente como decorrência do ambiente físico [...] ou de combinação de pessoas [...]. Muito mais do que isso, um contexto se constitui pelo que as pessoas estão fazendo a cada instante e por onde e quando elas fazem o que fazem(ERICKSON; SHULTZ, 1981, p. 277)

Através da forma com que os interagentes interpretam e sinalizam as ações uns dos outros, emerge a noção de enquadre. A noção interativa de enquadre se refere à definição do que está acontecendo em uma interação, sem a qual nenhuma elocução (ou movimento ou gesto) poderia ser interpretado. Para compreender qualquer elocução, um ouvinte (e um falante) deve saber dentro de qual enquadre ela foi composta. (TANNEN; WALLAT, 2002, p.188). Na sala de aula, o enquadre é, em princípio, estabelecido institucionalmente; consiste em acordo tácito entre professor e alunos. Porém, a relação entre os participantes gera outros enquadres, que podem emergir conforme se estrutura localmente essa interação. O modo como esses enquadres diferentes são encarados e manipulados pelo professor muitas vezes é determinante no modelo de interação predominante na sala.

\subsection{As relações de andaimagem}

As situações em que um estudante presta assistência a outro(s) colega(s) podem indicar que eles irão construir coletivamente um conhecimento acerca do tópico de estudo. As pesquisas de Alice Macpherson(2007) apontam para isso. A autora destaca que esses momentos de colaboração entre os discentes podem propiciar a chamada aprendizagem colaborativa. Segundo a autora, esse tipo de aprendizagem

[...] é um conjunto de técnicas de ensino-aprendizagem em que os estudantes interagem entre si para adquirir e praticar elementos de estudo com objetivos de aprendizagem comuns. [...]A aprendizagem colaborativa é um modo formal de estruturação de atividades em um ambiente de aprendizagem que inclui elementos específicos destinados a aumentar o potencial de aprendizagem de forma rica e profunda. (MACPHERSON, 2007, p.12).

Johnson e Roger (1994) conceituam aprendizagem colaborativa como sendo a capacidade de trabalhar cooperativamente para a construção e manutenção das instituições sociais. Segundo os autores, há três padrões de interação entre os alunos: a competição, o individualismo e a colaboração.

O primeiro seria baseado na competição entre os alunos, que se engajam para se sobressair, para que exista "o melhor"; o segundo padrão se daria quando os estudantes agem individualmente, em função de uma meta, sem prestar atenção aos outros colegas e, por fim, o último padrão citado é o da colaboração, em que ocorre um trabalho cooperativo entre o grupo - todos se interessam pela aprendizagem de cada membro desse grupo.

Paraexaminar as relações de andaimagem observadas nas turmas que foram analisadas, e quese destacam quando há momentos de aprendizagem colaborativa, empregamos, como um dos instrumentos de organização de dados os mapas de sala. Esses mapas foram inspirados por leituras no campo da geografia cultural, que será brevemente delineado na próxima seção.

\subsection{Geografia cultural}

A geografia culturalé o campo da geografia humana que estuda os produtos e normas culturais e suas variações através dos espaços e dos lugares. Os estudiosos dessa área têm como foco a descrição e a análise de como as formas de linguagem, religião, artes, crenças, economia, governo, trabalho e outros fenômenos culturais variam ou permanecem constantes, de um lugar para outro e na explicação de como os humanos funcionam no espaço. 
Por que os indivíduos e os grupos não vivem os lugares do mesmo modo, não os percebem da mesma maneira, não recortam o real segundo as mesmas perspectivas e em função dos mesmos critérios, não descobrem neles as mesmas vantagens e os mesmos riscos, não associam a eles os mesmos sonhos e as mesmas aspirações, não investem neles os mesmos sentimentos e a mesma afetividade? (CLAVAL, 2001, p.34).

Uma das tarefas da geografia cultural é mostrar como os sistemas de valores se traduzem pelas articulações específicas do social. A ação humana é fundada sobre o instinto contextualizado, normatizado e canalizado pela cultura (CLAVAL, 1999, p. 82).

Empregamos a geografia cultural, neste artigo, para tratar da noção de espaço. De modo geral, tendemos a conceber o espaço como uma noção meramente física. Porém,Claval (1992) nos ensina que os lugares estão carregados de sentidos e impressões daqueles que os habitam. Em outras palavras, isso quer dizer que não se pode desvincular o território de seu contexto. Segundo Soares (2010, p.3):

O processo de simplificação do espaço 'real' até a elaboração de sua representação gráfica no mapa, evidenciando temas e dados relacionados à cultura (mapas de eventos ou ocorrências de manifestações), possui um profundo significado simbólico, político e econômico. Observando a maneira como os diferentes caracteres sociais e culturais se espacializam, potencializa-se a compreensão do espaço.

Ao observarmos a sala de aula em análise, percebemos que um indicador valioso das relações entre os alunos naquele grupo era a maneira como eles se organizavam dentro daquele espaço físico, criando espaços sociais que delimitavam territórios e que, por outro lado, estabeleciam alianças. Ao montarmos mapas que se sucediam no tempo, fomos capazes de perceber como esses espaços sociais forma se modificando.

\subsection{Cultura}

Tomamos mais uma vez as palavras de Paul Claval, que nos informa que "[...]a cultura é a soma dos comportamentos, dos saberes, das técnicas, dos conhecimentos e dos valores acumulados pelos indivíduos durante suas vidas e, em uma outra escala, pelo conjunto do grupos de que fazem parte." (CLAVAL,1999, p.63).

Claval afirma que a transmissão desses valorestem seu início no ambiente familiar, na primeira infância e na adolescência, por intermédio do processo de imitação dos gestos do adulto, quando cada gesto ganha um valor relevante, pois o gesto e a palavra darão origem a rituais, sendo que cada cultura tem os seus: "É na família que o adolescente é instruído sobre os rituais e mitos próprios à religião, à ideologia de seus pais ou àquela que domina na sociedade da qual faz parte”. (CLAVAL,1999, p.63).

O que nos interessa mais de perto nesse conceito de cultura é o fato de estarmos lidando, ao analisar uma turma de alunos de língua estrangeira, não apenas com aprendizes de uma língua, mas com interagentes que trazem para um grupo suas próprias concepções sobre comportamentos, saberes, técnicas e conhecimentos, advindos de sua vivência em sociedades diferentes.

O fato de estarem no Brasil, longe de sua cultura, os faz, muitas vezes, olhar para ela de modo diferente. Mas, antes que esse processo se concretize, esses alunos passam por um outro processo que inclui o estranhamento não apenas da cultura brasileira, na qual estão agora imersos, mas da cultura de seus companheiros. Quando um grupo heterogêneo de pessoas se reúne na sala de aula, a formação do espaço comum não é tão simples como parece. É preciso um tempo para que cada um tome seu lugar, reconheça-o como seu, naquela nova configuração. Nem todos se saem igualmente bem na tarefa: uns se jogam no desconhecido, em busca do novo conversam com estranhos, olham para seus colegas, interagem. Outros, inseguros ou tímidos, ou ainda tensos com a proximidade do diferente, refugiam-se em livros, notebooks e na presença institucionalizada do professor para aprender. Pouco afeitos à exploração, preferem a segurança do conhecido e perdem oportunidades. É o que veremos nas próximas seções deste artigo.

\section{METODOLOGIA}

Utilizamos uma metodologia de caráter qualitativo e de base etnográfica. A análise foi feita em duas salas de português como língua estrangeira multiétnicas em uma universidade de Minas Gerais. São alunos intercambistas de outras universidades, jovens adultos, 
com idades entre 18 e 24 anos.

[...] a expressão "pesquisa qualitativa" designa uma gama de estratégias de pesquisa apresentando uma característica em comum: o privilégio à compreensão do sentido dos fenômenos sociais para além da sua explicação, em termos de relação causa e feito. (MONTEIRO, 1998 apud MONTEIRO, 2005, p. 4).

É comum que qualquer docente tenha múltiplas realidades em sua turma, principalmente no ambiente pesquisado, em que a multiculturalidade entre os discentes é evidente - o que favorece ainda mais a adoção da Etnografia. Segundo Trudgill (2000), a etnografia representaria o "[...] estudo das regras de interação comunicativa em ambiente transcultural” (TRUDGILL, 2000, p.113). Nessa perspectiva, tal corrente enquadra-se perfeitamente ao objeto de estudo, uma turma multiétnica de português como Língua Estrangeira.

Já em relação aos outros métodos adotados, Greg Myers (2002) discute a análise da conversação e da fala como uma técnica que se concentra não no levantamento de grandes quantidades de dados de pesquisa, mas na observação e na análise dos momentos reais de fala, das interações específicas nos momentos reais de fala e nas interações específicas em situações particulares. Myers explicita a importância da interação entre o pesquisador e o pesquisado e, de igual maneira, as circunstâncias da interação. Assim, o que move a análise da conversação é a forma como “[...] os participantes organizam a interação momento a momento” (MYERS, 2002, p.272).

Os instrumentos utilizados nesta pesquisa foram: uma gravação em áudio e vídeo de uma aula em uma turma de Português como Língua Estrangeiraem uma universidade de Minas Gerais;entrevistas escritas feitas com os estudantes;um conjunto de mapas de sala, que registraram a ocupação espacial espontânea dos discentes durante dez aulas; um diário de campo com descrições detalhadas de todos os eventos considerados relevantes por nós durante a observação das aulas da turma ao longo de dois semestres letivos. Neste artigo, apresentaremos os dados coletados na segunda turma de português para estrangeiros.

A gravação da aula consistiu em uma experiência de registro de uma aula completa. Realizada no início da pesquisa, essa gravação serviu para uma observação detalhada dos eventos da sala de aula.

As entrevistas feitas com os estudantes tiveram como objetivo conhecer um pouco mais sobre a interação de cada aluno com os demais e com outras pessoas.

O diário de campo foi o instrumento empregado para registrar, ao longo de dois semestres consecutivos de observação da sala de aula, tanto a rotina da sala, com os temas discutidos, as atividades executadas, como fragmentos das interações entre os alunos entreouvidas pela pesquisadora ou observadas por ela. Essas informações constituem recuso valioso para uma pesquisa de campo e foi a leitura dele que fomentou atémesmo a ideia de se anotar sistematicamente, na segunda turma observada, os lugares ocupados pelos alunos.

Em relação aos mapas de sala, estes foram concebidos para que pudéssemos analisar como os estudantes espontaneamente se posicionavam em sala de aula, isto é, qual carteira ocupavam regularmente, se havia deslocamento, se havia par(es) etc. Buscamos relacionar esses elementos com as atitudes e crenças demonstradas ou anunciadas por eles. A proximidade física e o entrosamento entre os pares poderiam dar ensejo à formação de grupos, que propiciariam ou não a ocorrência das atividades colaborativas, foco de nossa análise.Ao observar essa sequência de mapas de sala, temos um instrumento metodologicamente útil para buscarmos o entendimento da forma como as redes de relacionamento interpessoal entre os discentes são tecidas, de forma que possamos observar as ligações entre aquelas crenças e posicionamentos que eles já possuem, que trouxeram consigo de seu país de origem, com aquelas ideologias e manifestações culturais que vão sendo acrescidas e/ou transformadas a partir da experiência do intercâmbio.

Ao construirmos os mapas de sala realizamos um estudo de Geografia Cultural, já que relacionamos noções de cartografia com aspectos culturais.

Segundo as ideias de Claval (1992) e Cosgrovel (1998a, 1998b apud ROSENDHAL; CÔRREA, 2010, p.124-125), os lugares estão 
carregados de sentidos e impressões daqueles que os habitam, isto é, não se pode desvincular o território de seu contexto.

Por isso, analisamos os locais ocupados por cada um no espaço da sala de aula; já que a partir das concepções dos autores acima, acreditamos que o lugar ultrapassa a noção de espaço físico, revelando as noções de pertencimento do indivíduo.

\section{ANÁLISE DE DADOS}

Nesta seção, iremos sintetizar algumas análises realizadas na pesquisa. Essa parte compreenderá, inicialmente, as interações verbais e não-verbais dos alunos; logo após serãoapresentados resultados das observações coletadas no diário de campo e nos mapas de sala e, por fim, faremos um entrecruzamento entre todos os instrumentos de pesquisa.

4.1.Interações verbais e não-verbais entre os estudantes

Para mostrarmos o fenômeno de andaimagem entre alunos na turma de Português para estrangeiros (doravante PLE), apresentaremos aqui trecho de uma aula da primeira turma observada.

A aula que foi gravada e transcrita estruturou-se em duas partes: uma atividade voltada para conteúdos gramaticais e a outra que teve como foco o desenvolvimento de habilidades orais nos alunos. A metodologia utilizada pela professora por si só já possibilitava a ocorrência de andaimagens, já que ela apresentava frases e discutia com eles possibilidades de reescrita da sentença dada. O mesmo ocorria nas atividades orais, em que verificamos ocorrências de apoio à fala dos alunos tanto pela professora quanto por um colega.

Um momento que demonstra como se deu o processo de construção do conhecimento é o que apresentamos no recorte. Nele, a professora (aqui chamada de Carla) apresenta duas frases obtidas em textos dos alunos e propõe um trabalho de reestruturação. $\mathrm{O}$ aluno Kano (nome fictício de um aluno japonês) dá início a uma resposta, que é orientada pela professora e completada por Joana e pelo alunoPierre. Vejamos: ${ }^{2}$

1 Carla meus $\uparrow$ caros $(1.0)>$ pronto? $\uparrow<(0,2)>$ foi? $<(1.0)$ nessa aula de hoje $(0,2)$ nós vamos trabalhar $(0,2)$ com:: duas partes $(0,2)$ na primeira (.) eu aproveitei (.) uma um monte de tex:tos de vocês $(0.2)>$ um monte na verdade<, textos de cinco de vocês só $(0.2)$ para $(0.2)$ fazer uma espécie de:: arrumação da casa (0.2) de gramática (0.2) problemas que apareceram nos textos (.) e que podem aparecer nos textos de outros alunos também (.) Certo? (.) e que são bastante comuns na:: (1.2) são erros bastante comuns nos ${ }^{\circ}$ textos de vocês ${ }^{\circ}$, ok? (1.0) é:: eu fiz o seguinte (0.2) digitei uma listinha deles (0.2) tá ok? e aí vamos ver um por um (0.8) pra vê o que é que tem de (0.2) curioso $\downarrow$. os dois primeiros (1.0) são da mesma pessoa e eu queria ver o quê que vocês acham que (0.2) aconteceu aí. (4.0) quem é que descobre qual é o erro que aparece aqui? (0.8) "são duas cidades muita diferentes" (0.8) e "a cultura dela é muita rica" (6.5) (tentativa)? (.) oi? (3.0) quem个 me ajuda? (1.5) O quêé que tem de errado?

2 Kano Muita.

$(0.2)$

3 Carla porquê?

4 Kano tinha que sê:: "muito".

${ }^{2}$ A transcrição aqui apresentada tem como basea proposta Gago (2002). 
5 Carla "muito rica" (0.2) isso mesmo (0.2) O que acontece aqui? (1.0) esse::

6 Ivan ( )

7 Chris $\mathrm{A}(\mathrm{h})(\mathrm{h})(\mathrm{h})$

8 Shun agora que eu entendi!

(1.6)

9 Carla muito rica (0.8) muito (1.0) diferente ((escreve no quadro))

10 Pierre mas "muita” não existe?

11 Carla muitas pessoas

12 Joana isso. muitas pessoas. $>$ ficou perfeito $<$

13 Carla =muita água (.) Isso

No exemplo acima percebemos como ocorre a construção conjunta do conhecimento acerca da melhor forma de corrigir a frase "são duas cidades e muita diferentes", a partir da dinâmica proposta por Carla: ela faz as perguntas de modo a estimular a participação dos alunos ("por quê?", "quem me ajuda?") e direciona as respostas ao passo que um aluno ajuda o outro a completar sua resposta(Kano e Pierre), Pierre faz uma pergunta de modo a solicitar que a professora complete a explicação sobre concordância ("mas muita não existe?"). Além disso, a aluna da graduação em Letras, Joana, possivelmente influenciada pela dinâmica da interação, também auxilia dando exemplos para facilitar a explanação da docente (“= água=”).

A observação dos diários de campo indicou que foram muitas as ocorrências de andaimagem entre os alunos. Um exemplo, que aconteceu regularmente, foi o daaluna alemã, que ajudava seu colega alemão com explicações em sua língua materna, já que, por ser filha de uma brasileira, ela dominava de maneira mais eficiente a língua portuguesa. Com o tempo, ela passou ae pôde ajudar não só seu colega alemão, bem como os demais. O maior domínio em relação às práticas da língua favoreceu o processo de socialização do aluno alemão que, por sua vez, não se interessava menos pelo estudo e também pedia ajuda aos colegas e ao professor, quando necessário.

Os dois estudantes japoneses, que já estavam há mais tempo no Brasil, também ajudavam, conforme registros, os demais alunos no espaço da sala de aula, por meio de auxílio com termos desconhecidos da língua, fazendo desenhos no quadro-negro; também convidavam seus colegas para saírem e realizarem passeios a fim de conhecerem a cultura local, o que favorecia o processo de socialização dos estudantes. Aliadas a isso, também foram comuns as ocorrências em que os próprios alunos novatos se ajudavam e apoiavam seus outros colegas, como ocorreu em uma aula em que a aluna alemã levou um mapa da cidade de Juiz de Fora para a sala de aula e foi mostrando aos colegas algumas áreas do município para que pudessem se localizar e comentar sobre locais por onde já haviam passado.

Os elementos não verbais foram identificados nas amostras coletadas em vários momentos, revelando formas estratégicas que o aluno utiliza para melhor explicitar suas ideias. Há casos em que isso auxiliou na interação de alunos com menos proficiência na língua estrangeira.

A utilização de elementos não verbais pelos alunos, muito frequente na aula analisada, revelou o quanto eles estão familiarizados a esse modo de se comunicar. De forma espontânea, os alunos, em muitas das aulas observadas, íam ao quadro ou faziam gestos e se levantavam para desenhar e/ou representar seus pensamentos, ideias ou, simplesmente, para revelar seu cotidiano. Eles faziam isso 
na intenção de que todos os compreendessem da melhor forma possível.

Tais amostras de andaimagem evidenciam que a interação entre os alunos, embora muitas vezes vista como ameaça aos docentes, muitas vezes resulta em uma assistência mútua que favorece a compreensão da aula, a aquisição de novos conhecimentos e interfere positivamente na experiência de intercâmbio dos estudantes.

\subsection{Mapas de sala}

Os mapas de sala apresentados abaixo foram construídos com base em observação longitudinal da segunda turma de PLE. A proposta de construção desse instrumento de análise partiu dos dados obtidos no caderno de campo da pesquisadora, que indicava, ainda que de modo incipiente, um movimento entre os alunos ao longo das aulas no primeiro semestre que parecia ter relação com a aproximação entre eles e sua interação.

Na geografia cultural, o mapa é considerado não somente um artefato de localização de espaços territoriais, mas um instrumento de reconhecimento de relações humanas por meio de um sistema organizado e codificado. Ė nesse sentido que propomos os mapas de sala - como uma maneira de reconhecer movimentos dos alunos na sala de aula e triangular as informações daí decorrentes com as entrevistas feitas com eles e com a observação da professora e da pesquisadora durante o período das aulas.

Os mapas foram organizados por país de origem dos alunos, já que essa foi aorientação inicial que parecia guiar o relacionamento dos alunos.
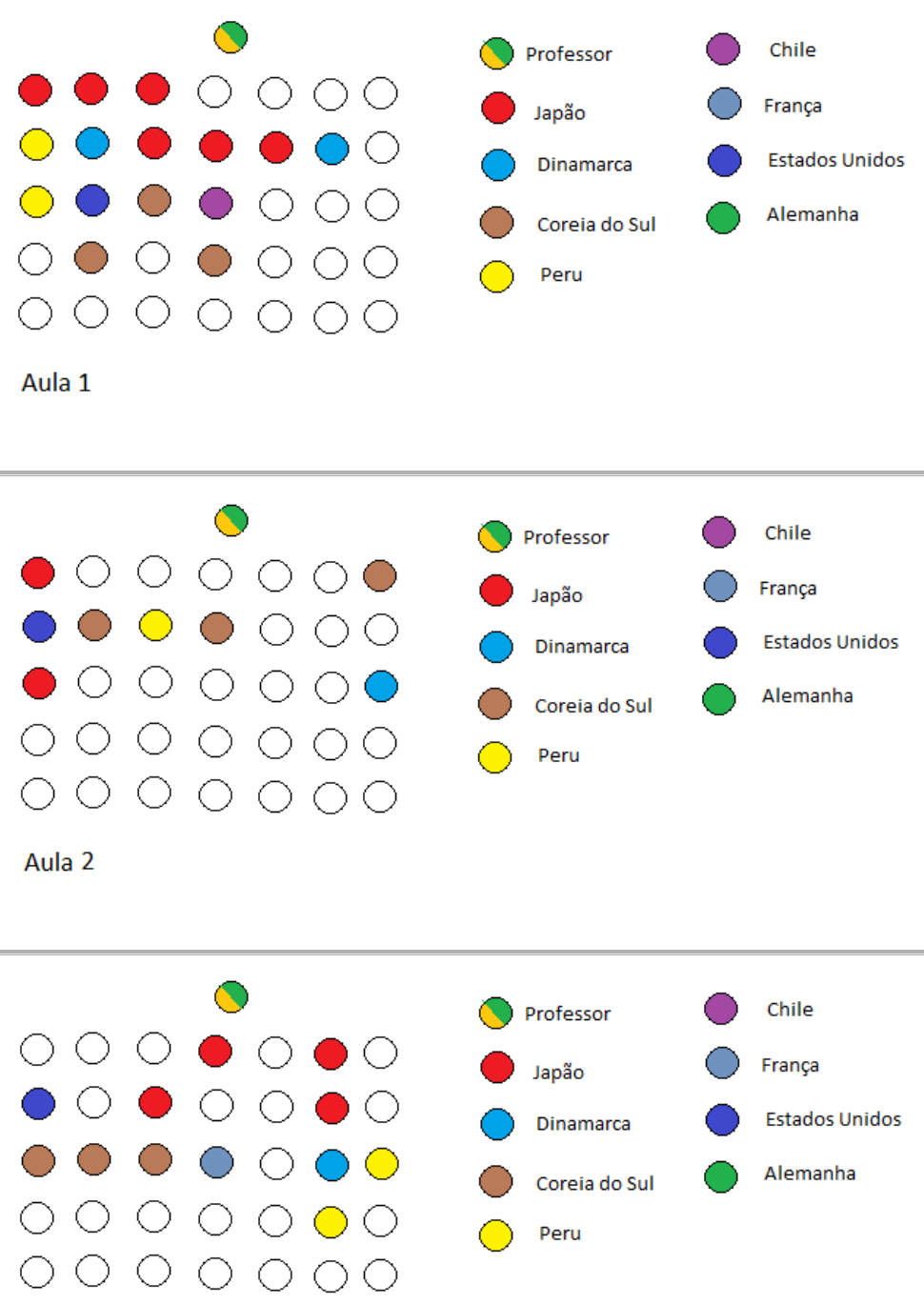

Aula 3 


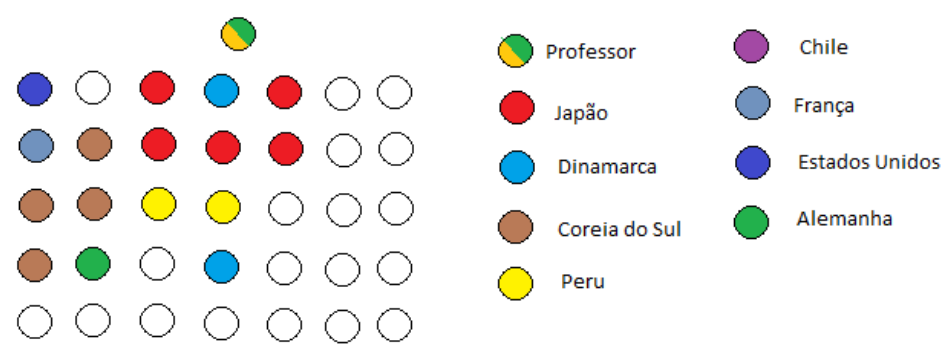

Aula 4

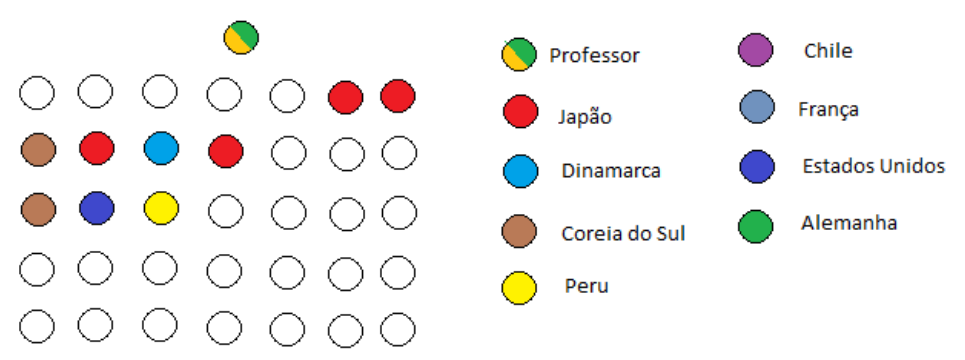

Aula 5
0000000
0000000
Professor
0 Chile
0000000
Јapão
$\bigcirc$ França
$\bigcirc$ Dinamarca
Estados Unidos
0000000
Coreia do Sul
Alemanha
0000000
$\bigcirc$ Peru

Aula 6

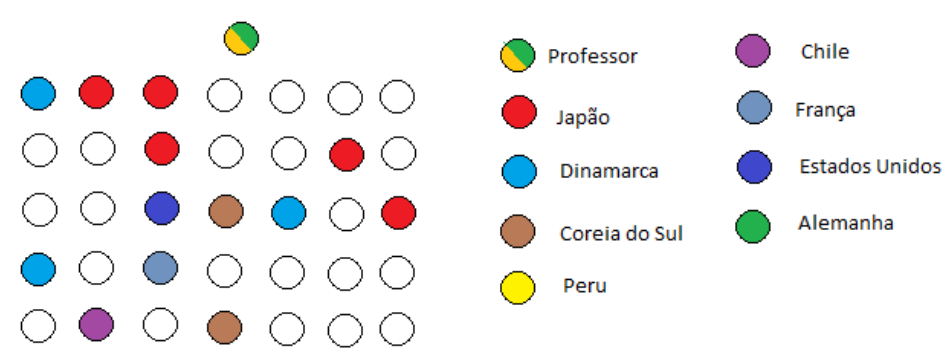

Aula 7 


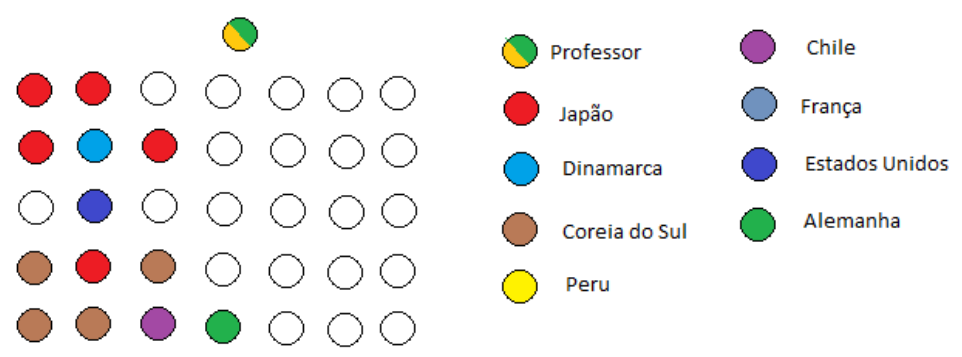

Aula 8

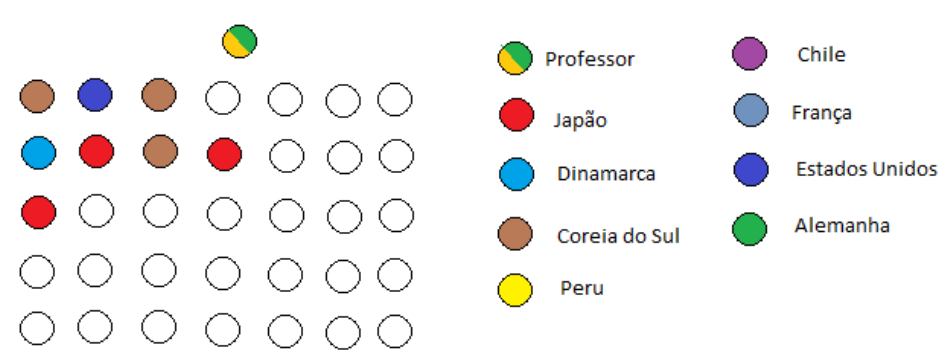

Aula 9

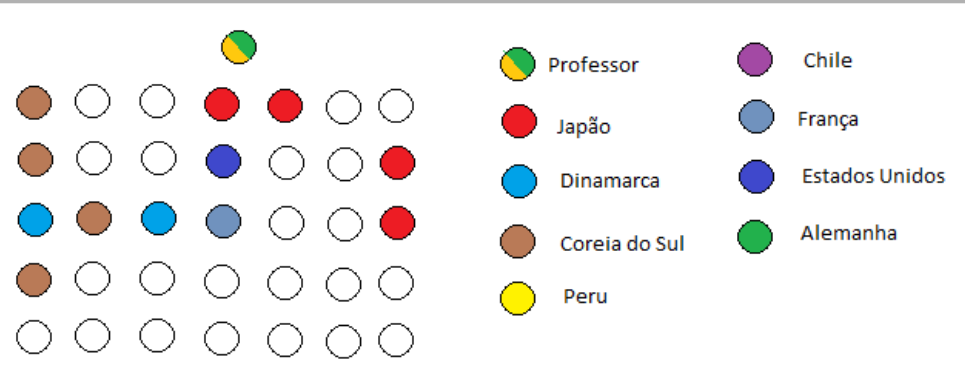

Aula 10

Os mapas são o resultado da observação continuada da pesquisadora que, durante dez aulas (em um período de aproximadamente seis semanas), passou a anotar onde cada um optava por se sentar. A escolha era determinada unicamente pelos próprios alunos, sem qualquer interferência da professora ou da pesquisadora. Embora determinadas situações, tais como chegar atrasado a uma aula, possam ter interferido nessa escolha, na maioria das vezes havia a disponibilidade de espaço, já que as salas comportavam um número maior de alunos do que os que havia na turma. Por isso, a escolha do próprio lugar indica, a nosso ver, uma disposição maior de conviver com determinado grupo de colegas. Foi o que se pretendeu analisar durante a observação das aulas.

A análise dos mapas e a observação dos diários de campo nos indicaram que houve a formação de grupos que se originaram devido a questões de identificação pessoal ou de nacionalidade. Além desses grupos, foi detectada a existência de alunos que não se enquadravam em nenhum dos grupos e se deslocavam em locais diversos no ambiente, configurando duas situações contrastantes: aqueles que interagiam satisfatoriamente com todos os grupos e aqueles que tinham alguns problemas de domínio da língua e enfrentavam problemas no relacionamento interpessoal.

Os grupos que se mantiveram até o final do período letivo foram aqueles compostos pelas japonesas, pelos sul-coreanos e um grupo formado pelos latinos (peruanos e chilenos). As meninas japonesas inicialmente ocuparam as primeiras fileiras e os sul-coreanos, por sua vez, procuraram se manter nas outras filas de carteiras. Ao conversarmos com as alunas, percebemos que esse afastamento tinha como motivo uma imagem estereotipada que tinham dos colegas, já que existe certa competição entre as duas culturas. Observamos também que, ao final do semestre letivo, tais estudantes já mantinham um relacionamento mais próximo, evidenciado 
pelos encontros extraclasse que a turma realizava e por maior familiaridade nas aulas. Apesar disso, a disposição espacial deles em sala de aula se manteve, conforme explanado no início do parágrafo.

O grupo dos sul-coreanos, em geral, reunia-se da segunda fileira para trás. Alguns deles, com exceção da aluna sul-coreana, tinham maior contato com o aluno francês que, de forma geral, relacionava-se com toda a turma. Conforme as informações coletadas e os mapas de salas relacionados, essa aproximação com os alunos sul-coreanos os ajudava,já que o aluno francês prestava auxílio aos colegas e colaborava com eles durante as atividades, estabelecendo, assim, uma aprendizagem colaborativa a partir de uma interdependência positiva entre eles.

O mesmo comportamento do aluno francês podia ser verificado no estudante norte-americano, pois ambos não ocupavam um lugar definido em sala de aula. Apesar de não fazerem parte de nenhum grupo, podiam transitar por eles sempre que quisessem, isto é, tinham um relacionamento amistoso com toda a sala e, como era perceptível que tinham um domínio maior dos aspectos formais e culturais da língua, sempre estavam dispostos a participar das atividades em sala com disposição e querendo apoiar seus colegas em suas dúvidas.

As alunas estudantes dinamarquesa (Dnk 3) e sul-coreana (SCorea 1), por sua vez, eram as que menos interagiam com os demais, apesar da proximidade física com os demais colegas. A sul-coreana mantinha-se exageradamente, conforme registros, ligada a seu dicionário eletrônico e se portava de forma muito tímida, o que dificultava sua interação com os outros colegas e, até mesmo, com a professora. Já a aluna dinamarquesa tinha pouco domínio da língua portuguesa, fator que interferiu negativamente no relacionamento com os colegas; ela também tinha como fonte principal de consulta o dicionário. A consequência desses comportamentos não teve reflexos positivos no processo de ensino-aprendizagem das discentes, já que a estudante sul-coreana enfrentou muitos problemas de adaptação e teve muitas dificuldades para finalizar o curso e a dinamarquesa saiu da turma antes da finalização do semestre letivo.

Observando o conceito de espaço, tal como delineado em seção anterior, observamos que os alunos configuram o espaço social da sala de aula como um campo marcado, por um lado, pela divisão oriunda de grupos previamente formados, seja por questões socioculturais (e aqui se destaca a nacionalidade), seja por afinidades de gênero (rapazes tenderam a se aproximar uns dos outros). Por outro lado, esse espaço social não é estático: o tempo decorrido nas aulas, as possibilidades de entrosamento engrendradas pelas atividades de colaboração possibilitam sua reconfiguração, ainda que parcial - já que as marcas sociais e as barreiras culturais não caem com facilidade e, alguns casos, não caem de maneira alguma.

\section{ANÁLISE DAS ENTREVISTAS}

A aplicação da entrevista com os estudantes visou à coleta de registros para relacioná-los com as informações do diário de campo e aos mapas de sala, no caso da segunda turma, de forma que pudéssemos checar os dados coletados em todos os instrumentos de pesquisa e triangular os resultados obtidos.

Em relação às nacionalidades dos estudantes, a entrevista demonstrou o perfil multicultural da turma, que era composta de um total de 13 alunos, dentre eles 2 peruanos, 1 norte-americano, 5 japoneses, 3 sul-coreanos, 1 dinamarquês e 1 francês.

Algumas das questões da entrevista tinham apenas a função de complementar a análise, sem interferência direta nos resultados; duas questões elucidam um pouco da relação dos alunos entre si e o modo como cada um enxerga a possibilidade de recorrer ao colega. É o que encontramos na questão 13 (reproduzida abaixo):

13- Em sala de aula, quando você tem uma dúvida, geralmente você prefere

( ) consultar um dicionário

( ) consultar seu professor

( ) consultar seu colega 
Na questão 13, os resultados foram: a alternativa referente ao uso do dicionário foi assinalada 4 vezes; a consulta ao professor foi marcada 4 vezes; a consulta ao colega foi grifada 7 vezes e 1 aluno marcou as três alternativas (várias opções poderiam ser assinaladas pelos alunos). Tal resultado nos indica que os alunos apoiam a existência de atividades de colaboração nesse grupo, já que 7 alunos, totalizando a maioria, pedem ajuda ao colega em um momento de dúvida durante as aulas. Esses mesmos alunos são os que, em outra questão do questionário, qualificam a experiência vivida como boa ou ótima, revelando nas aulas e nas atividades avaliativas os melhores rendimentos, além de serem aqueles que relatam fazerem algumas ou muitas amizades no Brasil. Aqueles que consultam apenas seu colega ou somente o professor aparentam, ao contrário do grupo anterior, ter dificuldades na convivência com os colegas, seja por questões de personalidade, por questões culturais ou mesmo de domínio da língua.

Analisando somente os dados do questionário, há uma sugestão de que a maior disposição dos alunos em participar de atividades colaborativas, seja tirando uma dúvida com o colega, seja ajudando-o, estava ligada à qualificação positiva da experiência de intercâmbio.

$5.1 \mathrm{O}$ entrecruzamento de todos os instrumentos de pesquisa

Nesta parte, relacionamos todos os instrumentos utilizados com o objetivo de investigar mecanismos que contribuíram para o processo de ensino-aprendizagem a partir da assistência entre os pares de estudantes.

Em relação à turma 1, os registros do diário de campo indicaram movimentos de (re)construção de identidade a partir da experiência do intercâmbio e da interação no espaço escolar. Tal manifestação ocorreu de forma mais evidente com os alunos japoneses, que chegaramnos primeiros dias de aula extremamente tímidos e, até mesmo, no caso da aluna, com um certo temor em relação ao que viria a enfrentar no país estrangeiro. Com o passar do tempo, como já foi indicado na análise, houve uma mudança na postura desses estudantes, que foram se mostrando cada vez mais adaptados ao país, descrevendo suas boas experiências e sentindo-se felizes no Brasil. Tais alunos, ao final do semestre, ressaltaram inclusive o desejo de voltar ao nosso país para cursar o Mestrado acadêmico. Além disso, eles eram os alunos que mais se destacavam em relação ao rendimento acadêmico e ao nível de proficiência. A aluna japonesa ainda encontrou um namorado brasileiro.

Contudo, o fato marcante em relação à questão da identidade está no depoimento dessa aluna japonesa no último dia de aula, conforme as informações do diário. Ela destacou que, ao passar um tempo no Brasil, sentiu uma forte vontade de "ser brasileira”, pois ela se "apaixonou" pelo país, pelos costumes, pela cultura etc. Foi nesse período que ela se engajou ainda mais nos estudos e buscou aprender sempre mais. Entretanto, ao final do período de intercâmbio, já prestes a voltar para seu país de origem, ela percebeu que não havia razão para "se tornar brasileira": ela percebeu que, apesar das mudanças,sua identidade de japonesa tinha sido conservada. Ela continuou sendo uma representante de seu país, apesar das mudanças ocorridas e das quebras de estereótipos negativos em relação ao Brasil.

A gravação da aula e as transcrições demonstraram que, tendo em vista o tamanho reduzido da turma, esta era unida e entrosada. Isso é observado em vários momentos de descontração e de familiaridade, quando eles falavam de suas vidas e se levantavam de seus lugares, sempre que precisavam, para ir ao quadro se expressar melhor ou simplesmente para falar em voz alta, de forma que todos pudessem compreender, ou seja, utilizavam recursos verbais e não verbais para se comunicarem de todas as formas possíveis, utilizando a língua portuguesa. Ao final do período letivo, as barreiras das diferentes culturas foram transpostas e o fato de todos serem intercambistas os uniu, de forma que sempre passeavam juntos, resultando esse contato em bons rendimentos no processo de aquisição da língua e cultura-alvo.

A turma 2, que era maior, teve a possibilidade de formação de mais grupos, diferentemente da turma 1, que se comportou predominantemente como um grande grupo único. E foi devido a essa formação que a construção dos mapas de sala foi possibilitada, para que pudéssemos verificar se existia uma regularidade nesses grupos. Aqueles que se mantiveram regulares, cujos alunos constantemente ocupavam relativamente os mesmos lugares, como os japoneses e os sul-coreanos, demonstraram menor tolerância em relação ao contato com outros grupos, principalmente no início do semestre letivo. Passado algum tempo, a convivência com os demais grupos melhorou, apesar de ainda haver restrições. Tais grupos, conforme os relatos do diário, interagiam mais entre si do 
que com o professor. As entrevistas também auxiliam nessa observação, já que, na questão em que se perguntava a quem eles recorriam quando tinham uma dúvida, houve 4 marcações no item dicionário, 4 alunos assinalaram que recorrem ao professor, 7 marcaram que recorrem ao colega e 1 marcou as três alternativas.

A entrevista não possuía identificação pessoal, contudo, ao relacionarmos com os dados do diário, podemos analisar que os grupos estáveis interagiam mais entre si. Já com relação aos alunos que não possuíam lugar fixo e se mantinham interagindo satisfatoriamente com todos os demais e o professor (o francês e o norte-americano), provavelmente um deles tenha assinalado as três respostas possíveis do item que questiona as fontes consultadas por eles em caso de dúvidas (o dicionário, o professor e o colega). A consequência disso é que, após observar que eles colaboravam com todos os grupos e entre si, viveram uma boa experiência do intercâmbio (relato da entrevista) e também possuíam um desenvolvimento satisfatório, a nível oral e escrito.

Após as análises, consideramos que o relacionamento interpessoal entre os discentes dentro e fora do ambiente escolar influencia satisfatoriamente no processo de ensino-aprendizagem e pode facilitar a adaptação em país estrangeiro.

\section{CONSIDERAÇÕES FINAIS}

No trabalho enfocado, visamos à investigação de aspectos que contribuíssem para a construção da dinâmica interacional entre discentes na sala de aula de PLA.

Embora a temática recorrente na área seja a interação entre aluno e professor, aquela socialmente legitimada, acreditamos que a interação entre alunos pode levar a resultados satisfatórios, no que se refere à aquisição de conhecimentos e na socialização dos estudantes.

Nesse sentido, investigamos o processo interativo a partir da possibilidade de assistência entre eles, em que se formam grupos cooperativos de alunos que buscam o aprendizado coletivo e a inserção naquele ambiente social. Dessa forma, analisamos a construção de redes de relacionamento interpessoal entre eles, que culminariam com tais atividades.

Utilizamos como embasamento teórico para o desvelamento dessas redes o conceito de andaimagem proposto por Silva (2006), que se refere ao processo dialógico estabelecido entre os grupos para que, coletivamente, possam executar tarefas que individualmente não seria possível executarem.

Ao tratarmos da dinâmica interacional, optamos também pela adoção de conceitos da Sociolinguística InteracionalAturma possui um perfil multicultural, assim como qualquer realidade encontrada no espaço da sala de aula. Fizemos isso para um melhor entendimento da diversidade de práticas e ideologias de cada um, que refletem no comportamento dos indivíduos dentro e fora do espaço escolar.

Na seção referente à metodologia, revelamos alguns métodos utilizados, como a Etnografia e a Etnometodologia, além da Etnogeografia, escolhidos devido aos objetivos da pesquisa e os papéis desempenhados pelos participantes no contexto pesquisado. Os instrumentos adotados foram: uma aula gravada e transcrita, uma entrevista escrita, a construção dos mapas de sala e um diário de campo, fonte de registros de todos os passos da pesquisa.

Duas turmas de alunos intercambistas de diferentes nacionalidades foram analisadas e os resultados apontam para: a turma 1 apresentou-se como um grupo único e colaborativo, devido ao fato de ser uma turma pequena, que foi se entrosando através das atividades de conversação e descontruíram os estereótipos que possuíam. A consequência observada foi a ocorrência de uma experiência positiva no país e no aprendizado, conforme os relatos dos próprios alunos. Já a turma 2 era maior e seus grupos formaram-se por questões de nacionalidade e por alunos que não se inseriam em nenhum grupo. Os grupos dos japoneses e sulcoreanos se mantiveram estáveis durante o ano, apesar do contato entre esses grupos aumentar durante o semestre letivo.

Já para os alunos que não se inseriram em nenhum grupo, temos realidades distintas. Dois deles, o francês e o norte-americano, embora não possuíssem um grupo fixo, deslocavam-se entre todos os grupos e eram familiarizados com todos, revelando um 
desempenho satisfatório no aprendizado da língua e cultura. Já as outras duas alunas, uma sul-coreana e a dinamarquesa, apresentavam muitas dificuldades no domínio da língua e para sanar suas dúvidas, registros apontam para o uso principal de dicionários eletrônicos, o que dificultava o processo de ensino-aprendizagem de ambas, bem como o entrosamento com o restante da turma. O reflexo disso foi que uma delas abandonou o curso antes do semestre letivo acabar e a outra teve muitas dificuldades para fazê-lo.

Assim, diante de todas as análises realizadas, consideramos que as interações entre estudantesocorridas no ambiente da sala de aula são altamente produtivas, já que podem ocasionar a aprendizagem colaborativa. Tal aprendizagem pode estimular efeitos positivos no processo de ensino-aprendizagem, a partir da aquisição de conhecimentos e pode também auxiliar na inserção social dos estudantes.

\section{REFERENCIAS}

BARINO, E. J. A dinâmica interacional entre discentes em turmas de Português como Língua Adicional. 2014. 95f. Dissertação (Mestrado em Linguística) - Programa de Pós-Graduação em Linguística, Universidade Federal de Juiz de Fora, Juiz de Fora, 2014. Dissertação de mestrado.

CLAVAL, P. A Geografia cultural. Florianópolis: UFSC, 1999.

CLAVAL, P. O Papel da nova geografia cultural na compreensão da ação Humana. In: ROSENDAHL, Z.; CORRÊA, R. L. (Org.). Matrizes da geografia cultural.Rio de Janeiro,EDUERJ, 2001.

COSGROVE, D. A Geografia está em toda parte. In: CÔRREA, R.L.; ROSENDHAL, Z. Paisagem, tempo e cultura. Rio de Janeiro: EDUERJ, 1998. p. 18-23.

GAGO, P.C. Questões de transcrição em análise da conversa. Veredas, v. 6, n.2, p.89-113, 2002.

ERICKSON, Frederick; SHULTZ, Jeffrey. 'O quando' de um contexto. Questões e métodos na análise da competência social. In: RIBEIRO, Branca Telles; GARCEZ, Pedro M. Sociolinguística Interacional. São Paulo: Edições Loyola, 1981.

GUMPERZ, J. Convenções de contextualização. In: RIBEIRO, B. T.; P. M. GARCEZ (Org.). Sociolingüística interacional: antropologia, lingüística e sociologia em análise do discurso. Porto Alegre: AGE, 1998.

JOHNSON, David W.; ROGER, T.An overview of cooperative learning.In:THUSAND,J.;VILLA, A.; NEVIN, A. (Ed.)Creativity and

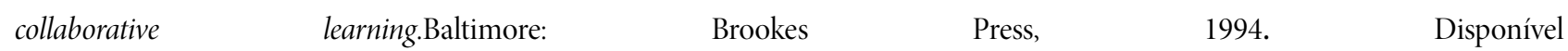
em:<http://teachers.henrico.k12.va.us/staffdev/mcdonald_j/downloads/21st/comm/BenefitsOfCL/OverviewOfCoopLrng_Benefi ts.html>.

MACPHERSON, A. Cooperative Learning - group activities for college courses, a guide for instructions. Kwantlen: University College, 2007.

MALAMAH-THOMAS, Ann. Classroom interaction. Oxford: Oxford University Press, 1987.

MYERS, G. Análise da conversação e da fala. In: BAUER, M.W. \& GASKELL, G. (Org.). Pesquisa qualitativa com texto, imagem e som: um manual prático. Petrópolis: Vozes, 2002.

MONTEIRO, R.A. Etnografia de espaços vivenciados: Reflexões e experiências. In: Espaços e identidades em processos de aprendizado e desenvolvimento. Juiz de Fora: Edições Feme, 2005.

Forum linguistic., Florianópolis, v.12,n.2, p.621-636, abr./jun.2015 
ROSENDAHL, Z.; CÔRREA, L. B.Temas e caminhos da geografia cultural. Rio de Janeiro: Ed. UERJ, 2010.

SILVA, V.B.F. Peerscaffolding: interlanguage development through collaborative dialogue. Tese (Doutorado) - Universidadee Federal Fluminense, 2006.

SOARES, F.S. Mapeamento cultural: uma proposta de leitura do espaço. 2010. 128f. Dissertação (Mestrado) - Programa de PósGraduação em Geografia, Brasília, 2010.

TANNEN, D.; WALLAT,C. Enquadres interativos eesquemas de conhecimento e interação:exemplos de um exame/consulta médica. In: RIBEIRO, B.T.; GARCEZ, P. (Ed.). Sociolinguística interacional. SP: Loyola, 2002.

TRUDGILL, P. Sociolinguistics: an introduction to language and society. London: Penguin Books. 2000.

Recebido em 10 / 06 / 2015. Aprovado em 14 / 07 / 2015. 